\title{
Method for Calculating the Static Characteristics of Radial Hydrostatic Compensator of Machine Tool Bearings Deformation
}

\author{
Vladimir A. Kodnyanko ${ }^{1 *}$ \\ ${ }^{1}$ Department of Standardization, Metrology and Quality Management, Faculty of Mechanics and Technology, \\ Siberian Federal University, Polytechnic Institute, Kirensky str. 26, 66074 Krasnoyarsk, Russian Federation \\ * Corresponding author, e-mail: kowlad@rambler.ru
}

Received: 20 September 2019, Accepted: 03 December 2019, Published online: 30 March 2020

\begin{abstract}
The design, mathematical model and methods of calculating static characteristics of the radial hydrostatic compensator of machine tool bearings deformation are considered. The research has shown that the design is able to provide a stable value of negative compliance in the range of small and moderate load values. It has been identified that the type of characteristics largely depends on the adjustment factor of the input choke hydraulic resistance, for which there is an optimal value in terms of the load characteristics stability. The example of calculating the compensator's parameters is given, and it is shown that the compensator is capable to provide the functions for the machine with real characteristics.
\end{abstract}

Keywords

hydrostatic bearing, hydrostatic compensator, compliance, negative compliance, zero compliance, load characteristics

\section{Introduction}

The durability, reliability and quality of work of transport vehicles are largely determined by the accuracy of machining of the main components and their parts on metal-cutting machines.

In the process of metalworking the Technological System (TS) of the machine tool deforms as a result of loads. Deformation leads to the displacement of the machine component parts, as a result the machine loses the ability to ensure machining accuracy partially or completely (Goddard, 1973). One of the ways to eliminate this drawback is to use devices that can compensate deformations in technological machine tool systems automatically (Blondeel et al., 1976a; Blondeel et al., 1976b; Blondeel et al., 1980; Kodnyanko, 2010; Kodnyanko, 2011; Kodnyanko and Kurzakov, 2017; Shatokhin et al., 1988; Shatokin and Shatokin, 1991; Shatokin et al., 2001).

The deformations of an ordinary technological system are characterized by its positive compliance. In order to achieve zero compliance (absolute stiffness) of an automatic TS it is necessary that the automatic deformational compensator included in this system has negative compliance equal to the absolute value of the conventional TS compliance.
Gas-static and hydrostatic bearings with active displacement compensators capable of providing negative compliance are known (Demin et al., 2008; Eresko et al., 2009). These structures are characterized by low energy consumption and the ability to compensate significant displacements in which other hydrostatic bearings, such as bearings of negative compliance with active compensation of lubricant consumption, would be inoperable. The bearings have stable load characteristics and satisfactory dynamics when operating in negative compliance modes (Kodnyanko, 2010).

The paper considers a compensator, which is a modification of a radial hydrostatic bearing with a limitation of the lubricant output flow. Structurally, the compensator is a container to place a passive TS bearing in it; together they provide a reduction of the machine tool compliance to zero.

\section{Compensator description}

Presented in Fig. 1 the radial hydrostatic compensator has housing 1 and sleeve 2, which are in contact with the elastic sealing rings 3 that can be deformed when the compensator perceives the force $f$ acting on the bearing (as an 
example rolling bearing 10 is shown in Fig. 1). The design also contains spring 4, which is in contact with housing 1 and sleeve 5 by its surfaces.

Lubrication enters the compensator through the slotted chokes 6 under constant pressure $p_{s}$, then enters cavity 7 under pressure $p_{c}<p_{s}$ and further, overcoming the hydraulic resistance of gap 8 with thickness h formed by the surfaces of sleeves 2 and 5, enters the drain through channels 9 .

To exclude circumferential lubricant overflows that negatively affect the compensator bearing capacity, gap 8 and cavities 7 are divided into a sufficient number $n$ of equal-sized sections using narrow longitudinal seals (not shown in Fig. 1).

To exclude circumferential lubricant overflows that negatively affect the compensator bearing capacity, gap 8 and cavities 7 are divided into a sufficient number $n$ of equal-sized sections using narrow longitudinal seals (not shown in Fig. 1).

The force $f$ acting on the sleeve 2 deforms the rings 3 , causing a radial displacement of this sleeve. As a result, there is a change in the hydraulic resistance and the profile of the gap 8 on the eccentricity $e_{1}>0$. This entails a change in the pressure $p_{c}$ in the cavities 7 and the gap 8 , resulting in a hydrostatic force $f_{c}$ opposite to the force $f$, which, acting on the sleeve 2 and both surfaces of the sleeve 5 , shifts the sleeve by the value of their eccentricity $e_{2}<0$, providing the bearing capacity of the compensator and reducing the eccentricity $e_{3}=e_{1}+e_{2}$ of the sleeve 2 and the housing 1 . The force $f_{c}$ is balanced by the force of elastic deformation of the spring 4 . With the increase in

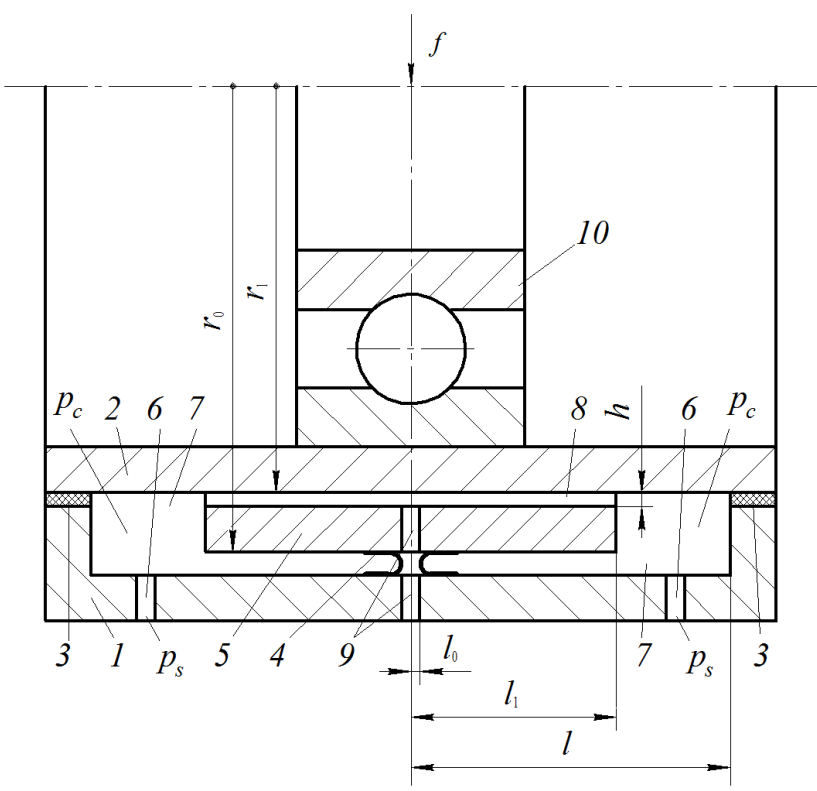

Fig. 1 The design scheme of the compensator the spring compliance $k_{s}$, at certain values of it, the compensator's compliance will become negative.

\section{Mathematical modeling and calculation method}

In the stationary mode, the pressure distribution function $p(z, \varphi)$ in the lubricant layer of thickness of gap $h(z, \varphi)=h_{0}-e_{1} \cos (\varphi)$ satisfies the boundary value problem for Reynolds differential equation (Booser, 1997; Khonsari and Booser, 2008)

$$
\left\{\begin{array}{l}
\frac{\partial}{\partial z}\left(h^{3} \frac{\partial p}{\partial z}\right)+\frac{\partial}{\partial \varphi}\left(h^{3} \frac{\partial p}{\partial \varphi}\right)=0 \\
p\left(l_{0}, \varphi\right)=0, p\left(l_{1}, \varphi\right)=p_{c}(\varphi), \\
p\left(l_{0}, 0\right)=p\left(l_{0}, 2 \pi\right), \\
p\left(l_{1}, 0\right)=p\left(l_{1}, 2 \pi\right),
\end{array}\right.
$$

where $z$ and $\varphi$ are the longitudinal and circumferential coordinates, $h_{0}$ is the thickness of the gap 8 with no load on the compensator.

The calculation of the static characteristics of the compensator is carried out in a dimensionless form. The scales of basic values taken are as follows: radius $r_{0}$ for linear dimensions, $p_{s}$ for pressures, $r_{0}^{2} p_{s}$ for forces, $h_{0}$ for gap 8 and eccentricities, $h_{0}^{3} p_{s} / \mu$ for volumetric lubricant consumption through slotted chokes 6 and 8 , where $\mu$ is lubricant viscosity. Further, the dimensionless values are indicated by uppercase Latin or lowercase Greek letters.

The presence of narrow longitudinal seals makes it possible to consider the lubricant flow in gap 8 to be one-dimensional, which simplifies the problem (Eq. (1)) considerably. In this case, the solution of its dimensionless analog is the function

$$
P(Z, \varphi)=P_{c}(\varphi) \frac{Z}{A_{h}},
$$

where $A_{h}=L_{1}-L_{0}$.

The function $P_{c}(\varphi)$ can be found from the condition of lubricant flow rate equality at the inlet and outlet of cavities 7 (Al-Bender and Van Brussel, 1992; Bhushan, 1999; Voskresensky et al., 1983). Using the well-known formulas to determine lubricant consumption through chokes 6 and 8 of the respective sections, we obtain

$$
H^{3} P_{c}=A\left(1-P_{c}\right) \text {. }
$$

Here $H(\varphi)=1-\varepsilon_{1} \cos (\varphi)$ is function of the dimensionless thickness of gap 8, $A$ is dimensionless parameter of chokes 6 .

Parameter $A$ can be determined from the Eq. (3) under the condition that there is no load on the compensator, 
when $H=1$, all eccentricities are zero, the pressure $P_{c}$ is constant and equal to a certain parameter, which is convenient to use as an input when adjusting hydraulic resistance of the mentioned chokes (Byant et al., 1986).

Then $A=\chi /(1-\chi)$, and the pressure in cavities 7 can now be calculated by the formula

$$
P_{c}(\varphi)=\frac{A}{A+H^{3}} .
$$

Taking into account the adopted scales, the hydrostatic force acting on the surface of sleeves 2 and 5 in the area of gap 8 can be determined by the formula

$$
W_{h}=2 \int_{0}^{2 \pi} \int_{L_{0}}^{L_{1}} P(Z, \varphi) \cos \varphi d Z d \varphi=A_{h} J
$$

where

$$
J=A \int_{0}^{2 \pi} \frac{\cos \varphi d \varphi}{A+H^{3}} .
$$

The hydrostatic force acting on the surface of the sleeve 5 from the spring 4 , we define the same way

$$
W_{s}=2 R_{1} \int_{0}^{2 \pi} \int_{L_{0}}^{L_{1}} P_{c}(\varphi) \cos \varphi d Z d \varphi=A_{s} J
$$

and, finally, the hydrostatic force acting of the surface of sleeve 2 in cavities 7 is found by the formula

$W_{c}=2 \int_{0}^{2 \pi} \int_{L_{1}}^{L} P_{c}(\varphi) \cos \varphi d Z d \varphi=A_{c} J$,

where $A_{s}=2 A_{h} R_{1}, A_{c}=2\left(L-L_{1}\right)$.

When calculating the eccentricity $\varepsilon_{3}$, compliance $K=$ $d \varepsilon_{3} / d F$ and load $F$, the following parameters are used as input ones: lengths $L, L_{0}, L_{1}$, outer radius $R_{1}$ of sleeve 5 , factor $\chi$, coefficient Ks of radial compliance of spring 4. Neglecting o-rings 3 compliance, the equation of the relationship between the eccentricities and of the force balance disks 2 and 5 can be written in a convenient form for calculations

$\varepsilon_{2}=K_{s}\left(W_{h}-W_{s}\right), \varepsilon_{3}=\varepsilon_{1}+\varepsilon_{2}, F=W_{h}+W_{c}$.

Taking the eccentricity $\varepsilon_{1} \in[0,1]$ as a variable value when calculating the load characteristics of the compensator, the integral (Eq. (6)) was sequentially calculated, the pressure in cavities 7 was calculated by formula (Eq. (4)), then hydrostatic forces were found using formulas (Eqs. (5), (7), (8)) and, finally, using formulas (Eq. (9)), using the formulas (Eq. (9)), we determined total eccentricity $\varepsilon_{3}$ and force $F$
$\varepsilon_{3}\left(\varepsilon_{1}\right)=\varepsilon_{1}+K_{s}\left(A_{h}-A_{s}\right) J\left(\varepsilon_{1}\right)$,

$F\left(\varepsilon_{1}\right)=\left(A_{h}+A_{c}\right) J\left(\varepsilon_{1}\right)$.

After differentiating (Eq. (9)) with respect to $\varepsilon_{1}$, the compensator compliance formula is obtained

$K=\frac{\partial \varepsilon_{3}}{\partial F}=\frac{1-K_{s}\left(A_{s}-A_{h}\right) J_{1}}{\left(A_{h}+A_{c}\right) J_{1}}$,

where

$J_{1}=\frac{\partial J}{\partial \varepsilon_{1}}=3 A \int_{0}^{2 \pi}\left(\frac{H \cos \varphi}{A+H^{3}}\right)^{2} d \varphi$.

The integrals $J$ and $J_{1}$ were calculated by the Simpson rule (Dwight, 1961).

\section{Research results and discussion}

Figs. 2 to 4 represent the results of the calculation of the characteristics of the compensator for $R_{1}=1.1 ; L_{0}=0.01$; $L_{1}=0.15 ; L=0.4$.

Fig. 2 shows the load dependences of $\varepsilon_{3}(F)$ for various values of the coefficient $K_{s}$ of the spring 4 compliance (see Fig. 1). The sampling frequency of these dependences is determined by the parameter $K_{s 0}$, at which the compensator has zero compliance in the neighborhood of $F=0$.

When $K_{s}=0$ that corresponds to absolutely rigid spring 4, the compensator has a positive compliance $K=K_{0}$, at which bearing 10 subsides under the load in the compensator just increasing the TS compliance.

With increasing $K_{s}$, the compliance of the structure decreases gradually and, at $K_{s}=K_{s 0}$, the compensator reaches zero compliance (absolute rigidity) in the range of low and medium loads.

When $K_{s}>K_{s 0}$, the compensator acquires negative compliance $K<0$ and, therefore, the ability to compensate for

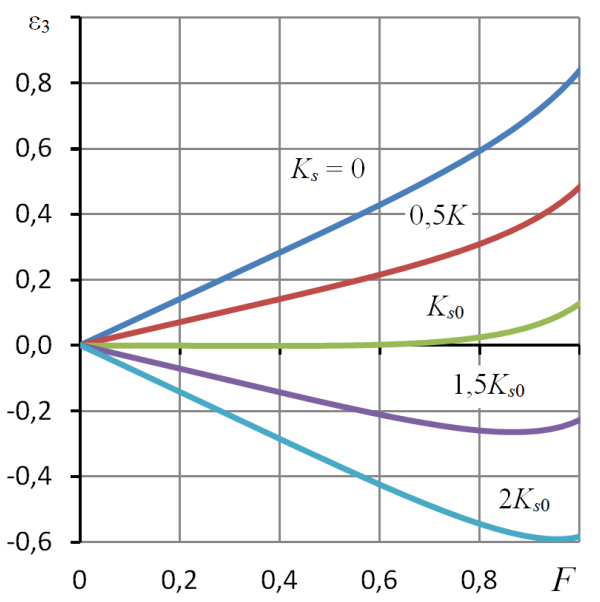

Fig. 2 Dependences of $\varepsilon_{3}(F)$ for different values of $K_{s}$ at $\chi=0.37$ 


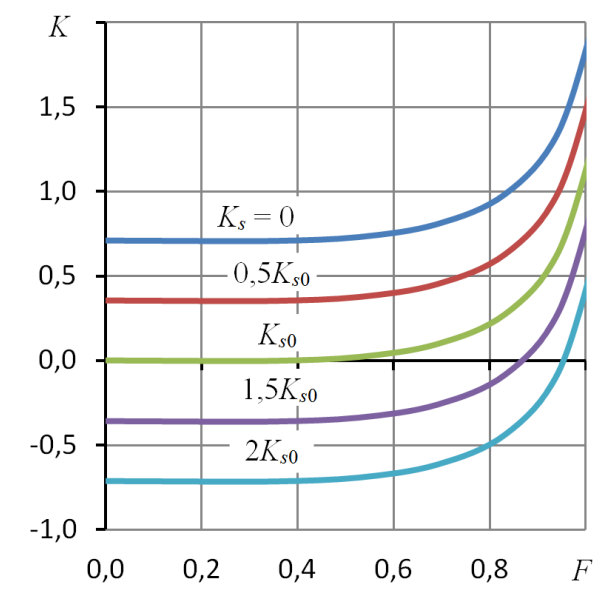

Fig. 3 Dependences of $K(F)$ for different values of $K_{s}$ at $\chi=0.37$

the TS deformation automatically. Thus, at $K_{s}=2 K_{s 0}$, the compensator has negative compliance, which, in absolute value, is equal to the positive compliance of the structure with a rigid spring $\left(K_{s}=0\right)$.

A visual representation of the compensator compliance $K$ is given by the curves shown in Fig. 3. It can be seen that the compensator has almost zero instability $N_{k}=d K / d F \approx 0$ of the compliance magnitude (a measure of load characteristic non-linearity) in the range of small and moderate forces $F \leq 0.42 F_{\max }$, where $F_{\max }$ is the maximum load on the structure.

These conclusions allow writing simple approximate dependencies of the compensator compliance $K$ and the eccentricity $\varepsilon_{3}$ on the compliance $K_{s}$ of spring 4 for the mentioned range

$K=K_{0}\left(1-\frac{K_{s}}{K_{s 0}}\right) ; \varepsilon_{3}=K_{0}\left(1-\frac{K_{s}}{K_{s 0}}\right) F$.

On the same basis, in the range of the compensator stable compliance, the values of $K_{0}$ and $K_{s 0}$ can be found by integrating (Eq. (6)) in the vicinity of small $\varepsilon_{1}$, for which dependences following from Taylor formula are valid

$J=A_{j} \varepsilon_{1}, A_{j}=\frac{3 \pi A}{(1+A)^{2}}=3 \pi \chi(1-\chi)$.

Taking into account (Eq. (14)) and (Eq. (9)), in this range the compensator compliance can be found by the formula

$K_{0}=\frac{1-K_{s} A_{j}\left(A_{s}-A_{h}\right)}{A_{j}\left(A_{c}+A_{h}\right)}$.

From (Eq. (15)) it is possible to obtain the formula of the spring compliance of the compensator with zero compliance $\left(K_{0}=0\right)$

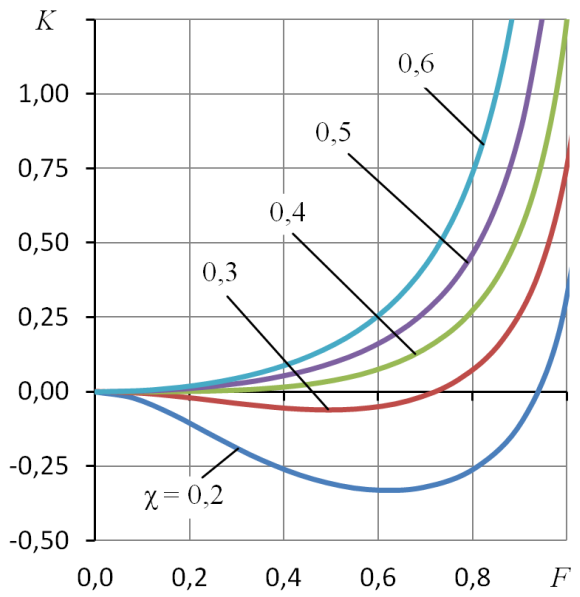

Fig. 4 Dependences of $K(F)$ for different values of the factor $\chi$

$$
K_{s 0}=\frac{1}{3 \pi \chi(1-\chi)\left(L_{1}-L_{0}\right)\left(2 R_{1}-1\right)} .
$$

Fig. 4 shows the graphs of the compliance $K$ dependence on force $F$ for various values of the adjustment factor $\chi$ under the condition that $K=-0.4$ with $F=0$. For small $\chi$ the compensator has a considerable margin of negative compliance, however, in the operating range of force $F$ change, compliance $K$ is characterized by its significant instability. With a larger $\chi$ by $F$ increase, the compensator compliance is growing rapidly that leads to a significant reduction in the range of low instability. Consequently, the best value of the factor $\chi$ from the point of view of the minimum criterion $N_{k}$ is in some intermediate range.

If we assume that the acceptable deviation of the characteristic $K$ from the initial value $K(0)$ is no more than $5 \%$, then the values of the parameters with minimal instability $N_{k}$ shown in Fig. 4 are characterized by curves $K(F)$, corresponding to $\chi=0.37$. In this case, the compensator ensures stable compensation of the TS deformation to $F=0.48 F_{\max }$.

\section{An example of the calculation of the compensator}

We calculate the characteristics of the hydrostatic compensator, providing zero compliance of the $\mathrm{CNC}$ horizontal boring machine (Mineev and Blinov, 2012), for which the radial load is $f=5000 \mathrm{~N}$ acting on the front end of the spindle, the value of the TS deformation at the spindle departure is $e_{d}=80 \mu \mathrm{m}$, angular contact bearings have an outer diameter of $d=280 \mathrm{~mm}$.

We will use the compensator for which the calculations and graphs are shown in Fig. 3.

The TS compliance is $k_{d}=e_{d} / f=0.16 \mu / \mathrm{kg}=1.510^{-8} \mathrm{~m} / \mathrm{N}$. 
Taking into account the size of the bearings' outer diameter, we put $r_{0}=160 \mathrm{~mm}$ and $h_{0}=160 \mu \mathrm{m}$. Then the TS dimensionless deformation is $\varepsilon_{d}=e_{d} / h_{0}=0.5$.

We assume $F=0.2$ which corresponds to the average load of the compensator stable compliance range. Using the force scaling formula, we calculate the value of lubricant pressure at the inlet of the compensator $p_{s}=f / r_{0}^{2} F=0.98 \mathrm{MPa}$.

The TS dimensionless compliance is $K_{d}=\varepsilon_{d} / F=2.5$. To compensate for the TS deformation fully, it is necessary to comply with the condition where $K+K_{d}=0$. Therefore, $K=-K_{d}=-2.5$. According to (Eq. (15)) and (Eq. (16)), $K_{0}=0.79$ and $K_{s 0}=3$.

Using the formula (Eq. (10)), we find $K_{s}=K_{s 0}$ $\left(1-K / K_{0}\right)=12.5$ and $K_{s} / K_{s 0}=4.1$. The compliance of the spring is $k_{s}=K_{s} h_{0} / r_{0}^{2} p_{s}=8 \cdot 10^{-8} \mathrm{~m} / \mathrm{N}$.

Thus, to ensure the TS zero compliance, the ratio of the compensator spring radial compliance $k_{s}$ to the TS compliance $k$ d should be $12.5 / 2.5=5$ in this case.

Using the formula (Eq. (13)), we find $K_{s}=K_{s 0}$ $\left(1-K / K_{0}\right)=12.5$ and $K_{s} / K_{s 0}=4.1$. The compliance of the spring is $k_{s}=K_{s} h_{0} / r_{0}^{2} p_{s}=8 \cdot 10^{-8} \mathrm{~m} / \mathrm{N}$.

Thus, to ensure the TS zero compliance, the ratio of the compensator spring radial compliance $k_{s}$ to the TS compliance $k_{d}$ should be $12.5 / 2.5=5$ in this case.

\section{References}

Al-Bender, F., Van Brussel, H. (1992) "Tilt characteristics of circular centrally fed aerostatic bearings", Tribology International, 25(3), pp. 189-197.

https://doi.org/10.1016/0301-679X(92)90048-R

Bhushan, B. (1999) "Principles and Applications of Tribology", John Wiley \& Sons, New York, NY, USA. [online] Available at: https://books.google.ru/books?id=C1Yfwty-b-UC\&lr=\&hl=en\&source=gbs_navlinks_s [Accessed: 01 December 2003]

Blondeel, E., Snoeys, R., Devrieze, L. (1976a) "Aerostatic Bearings with infinite Stiffness", Annals of the CIRP, 25(1), pp. 122-128.

Blondeel, E., Snoeys., R, Devrieze, L. (1976b) "Externally Pressurized Bearings with Variable Gap Geometries", In: 7th International Gas Bearing Symposium, Cambridge, UK, pp. 13-15.

Blondeel, E., Snoeys, R., Devrieze, L. (1980) "Dynamic Stability of Esternally Pressurized Gas Bearings", ASME: Journal of Lubrication Technology, 102(4), pp. 511-519. https://doi.org/10.1115/1.3251588

Booser, E. (1997) "Solid Lubricants, Tribology. Data Handbook", CRC Press, Boca Raton, FL, USA, pp. 156-158.

Byant, M. R., Velinsky, S. A., Beachly, N. H., Fronczak, F. J. (1986) "A Design Methodology for obtaining Infinite Stiffness in an Aerostatic Thrust Bearing", ASME: Journal of Mechanisms, Transmissions, and Automation in Design, 108(4), pp. 448-453. https://doi.org/10.1115/1.3258753

\section{Conclusion}

The study of the static characteristics of the TS radial hydrostatic deformation compensator shows that the design is capable of providing a stable negative compliance in the range of low and moderate loads. The type of these characteristics largely depends on the factor of the input choke hydraulic resistance adjustment $\chi$, for which there is an optimal value in terms of the load characteristics stability. The example of calculating the compensator parameters shows that it is capable of proving its functions for a machine tool with real characteristics.

The important properties of the compensator, which also affect its performance, are the stability and dynamic response of the structure to the force effect, which can be assessed by the speed and quality of the system dynamics based on the calculation and study of the non-stationary model of the compensator.

The dynamic characteristics of the compensator can be obtained and investigated on the basis of its mathematical model, which is based on the non-stationary Reynolds equation.

Demin, V., Pikalov, Y., Shatokhin, S. (2008) "Проектирование адаптивных гидростатических опор для шпиндельных узлов и направляющих металлорежущих станков" (Designing adaptive hydrostatic bearings with floating lubricant injection regulators for spindle assemblies and directing machine tools), Engineering technology, 9, pp. 27-30. (in Russian)

Dwight, H. B. (1961) "Tables of integrals and other mathematical data", The Macmillan Company, New York, NY, USA.

Eresko, S., Shatokhin, S., Shatokhina, L. (2009) "Встроенный двухпоточный плавающий регулятор для адаптивного нагнетания смазки в оппозитные несущие карманы замкнутых гидростатических направляющих" (Built-in double-flow floating regulator for adaptive injection of lubricant into opposed carrier pockets of closed hydrostatic guides), In: 2009 Scientific and Technical Conference, Bratsk, Russia, pp. 3-9. (in Russian)

Goddard, E. J., Cowley, A., Burdekin, M. (1973) "A Measuring System for the Evaluation of Spindle Rotation Accuracy", In: Tobias S. A., Koenigsberger, F. (eds.) Proceedings of the Thirteenth International Machine Tool Design and Research Conference, Palgrave, London, UK, pp. 125-131. https://doi.org/10.1007/978-1-349-01857-4_18

Khonsari, M. M., Booser, E. R. (2008) "Applied Tribology", WileyInterscience, London, UK. 
Kodnyanko, V. (2010) "Отрицательная податливость энергосберегающей адаптивной радиальной гидростатической опоры с ограничением выходного потока смазки" (Negative compliance of the energy-saving adaptive radial hydrostatic bearing with the restriction of the output flow), Journal of the Siberian Federal University. Technics and technology, 3, pp. 444-453. [online] Available at: http://elib.sfu-kras.ru/handle/2311/1864 [Accessed: 24 August 2010] (in Russian)

Kodnyanko, V. (2011) "Устойчивость энергосберегающей адаптивной радиальной гидростатической опоры с ограничением выходного потока смазки" (Stability of energy-saving adaptive radial hydrostatic bearing with restriction of the output flow of lubricant), Journal of the Siberian Federal University. Technic and technology, 6(4), pp. 907-914. [online] Available at: http://elib. sfu-kras.ru/handle/2311/2785 [Accessed: 1 September 2011] (in Russian)

Kodnyanko, V., Kurzakov, А. (2017) "Статические и динамические характеристики осевой гидростатической опоры с мембранным компенсатором перемещения" (Static and dynamic characteristics of axial hydrostatic bearing with a membrane compensator displacement), Assembly in mechanical engineering, instrument making, 18(2/199), pp. 82-87. [online] Available at: https://www.mashin.ru/files/2017/ve0817_web.pdf [Accessed: 22 September 2017] (in Russian)
Mineev, A., Blinov, O. (2012) "Исследование жесткости шпиндельного узла средствами твердотельного моделирования" (Investigation of the rigidity of the spindle assembly by means of solid modeling), Vestnik, 2, pp. 1-4.

Shatokhin, S., Kodnyanko, V., Zaitsev, V. (1988) "Функциональные возможности радиальной активной гидростатической опоры" (Functional capabilities of radial active hydrostatic bearing), Mashinovedenie, 4, pp. 85-91. (in Russian)

Shatokhin, S. N., Shatokhin, S. S. (1991) "Гидростатические подшипники с активно-подвижной опорой" (Hydrostatic bearings with an actively mobile bearing), Reliability of technological equipment, surface quality, friction and wear), Reports of the AllUnion Scientific and Technical Conference, Khabarovsk, Russia, Rep. 154. (in Russian)

Shatokhin, S., Pikalov, Y., Demin, V. (2001) "Адаптивные бесконтактные подшипники скольжения с плавающими регуляторами расхода смазки" (Adaptive non-contact sliding bearings with floating lubricant discharge regulators), Engineering technology, 9, pp. 29-33. (in Russian)

Voskresensky, V., Dyakov, V., Zile, A. (1983) "Расчет и проектирование опор жидкостного трения" (Calculation and design of the bearings of fluid friction), Mechanical Engineering, Moscow, Russia. (in Russian) 